\title{
Fructose induces gluconeogenesis and lipogenesis through a SIRT1-dependent mechanism
}

\author{
Paul W Caton, Nanda K Nayuni, Noorafza Q Khan, Elizabeth G Wood and Roger Corder \\ Department of Translational Medicine and Therapeutics, Bart's and the London School of Medicine and Dentistry, William Harvey Research Institute, \\ Queen Mary University of London, London EC1M 6BQ, UK \\ (Correspondence should be addressed to P W Caton; Email: p.w.caton@qmul.ac.uk)
}

\begin{abstract}
Consumption of a fructose-rich diet leads to insulin resistance and dyslipidemia in part due to elevated gluconeogenesis and lipogenesis. SIRT1, an $\mathrm{NAD}^{+}$-dependent protein deacetylase, can induce gluconeogenesis and lipogenesis. The aim of this study was to determine whether fructose increased hepatic SIRT1, leading to induction of gluconeogenesis and lipogenesis. Rat hepatocytes were incubated with fructose $(1-5 \mathrm{mM})$. SIRT1 protein, SIRT1 activity, and $\mathrm{NAD}^{+} / \mathrm{NADH}$ ratio were measured. The effects of SIRT1 inhibitors (EX-527 and nicotinamide) and activators (SIRT1 activator 3 and SRT1720) and the mitochondrial complex I inhibitor rotenone were examined on fructose-induced increases in gluconeogenesis and lipogenesis. Fructose increased SIRT1 protein, SIRT1 activity, and $\mathrm{NAD}^{+} / \mathrm{NADH}$ ratio. Fructose also induced gluconeogenesis, with increases in peroxisome proliferatoractivated receptor coactivator 1-alpha (PGC1 $\alpha$ ) and phosphoenolpyruvate carboxykinase (PEPCK; gene code Pck1)

gene expression, PEPCK activity, and hepatocyte glucose production. In addition, levels of 3-hydroxy-3-methylglutaryl coenzyme A reductase (Hmgcr) and acetyl-coA carboxylase $(A c c)$ mRNA, and intracellular cholesterol were increased. Increases in gluconeogenesis, Hmgcr, Acc, and cholesterol were abolished by SIRT1 inhibitors and rotenone, while SIRT1 activators increased gluconeogenesis, Hmgcr, Acc, Pgc1 $\beta$, and sterol regulatory element-binding protein 1c (Srebp1c) gene expression. In conclusion, fructose induces gluconeogenesis and lipogenesis through a SIRT1dependent mechanism, suggesting that induction of hepatic SIRT1 could play a pivotal role in the metabolic changes observed in humans and animals consuming a fructose-rich diet. These results highlight the need for a greater understanding of the role of SIRT1 in metabolic regulation and indicate the potential for adverse effects of SIRT1 activators if used therapeutically.

Journal of Endocrinology (2011) 208, 273-283
\end{abstract}

\section{Introduction}

Dietary sugar consumption has risen by more than $30 \%$ over the past 40 years with the widespread use of high fructose corn syrup as a sweetener in many foods and beverages being a major contributor to this increase (Bray et al. 2004, Gaby 2005, Johnson et al. 2007). The prevalence of obesity, metabolic syndrome, and type 2 diabetes mellitus (T2DM) has increased in parallel with sugar consumption, particularly fructose (Bray et al. 2004, Johnson et al. 2007). Consistent with this, even a modest daily intake of sugar-sweetened soft drinks or fruit juice is associated with weight gain or an increased risk of metabolic syndrome and T2DM (Bazzano et al. 2008, Malik et al. 2010).

In rodents, fructose feeding leads to onset of symptoms of the metabolic syndrome, including hyperglycemia, hyperinsulinemia as well as obesity, hypertension, and increased levels of triglycerides, fatty acids and cholesterol (Fiebig et al. 1998, Kelley et al. 2004, Jurgens et al. 2005, Bilz et al. 2006, Rajasekar \& Anuradha 2007, Nagai et al. 2009). In humans, consumption of a fructose-rich diet causes insulin resistance, increases uric acid, and stimulates de novo lipogenesis, resulting in increased levels of triglycerides, cholesterol, and small pro-atherogenic low-density lipoprotein particles (Hollenbeck 1993, Faeh et al. 2005, Nakagawa et al. 2006, Aeberli et al. 2007, Abdel-Sayed et al. 2008, Parks et al. 2008, Stanhope et al. 2009).

Induction of gluconeogenesis by overexpression of phosphoenolpyruvate carboxykinase (PEPCK; gene code Pck1) is sufficient to cause a T2DM-like state with insulin resistance and hyperglycemia (Valera et al. 1994, Sun et al. 2002), while knockdown of hepatic Pck1 corrected hyperglycemia and dyslipidemia in rodent models of T2DM (Gomez-Valades et al. 2006, 2008). Hence, observations that Pck1 gene expression and activity are increased in response to a high-fructose diet with elevated hepatic glucose production and hyperglycemia (Blakely et al. 1981, Rajasekar \& Anuradha 2007) could represent a key element of the metabolic response to excessive dietary fructose. Despite clear evidence for a relationship between excess fructose 
consumption and impaired glucose and lipid homeostasis, the mechanisms responsible have yet to be elucidated.

Recent studies have demonstrated the essential role of SIRT1, an $\mathrm{NAD}^{+}$-dependent protein deacetylase, in the regulation of hepatic gluconeogenesis. SIRT1 deacetylates peroxisome proliferator-activated receptor coactivator 1-alpha (PGC1 $\alpha$ ), a key coactivator of Pck1 gene expression, leading to increased hepatic glucose production (Rodgers et al. 2005, Rodgers \& Puigserver 2007). Hepatic SIRT1 also regulates the expression of genes controlling cholesterol and lipid metabolism and is able to induce lipogenesis (Rodgers \& Puigserver 2007, Chen et al. 2008). However, the specific nutrient signals that regulate hepatic SIRT1 have yet to be identified.

Activation of SIRT1 has been reported in the hearts of fructose-fed mice through increases in $\mathrm{NAD}^{+} / \mathrm{NADH}$ ratio (Pillai et al. 2008). Similarly, increased $\mathrm{NAD}^{+} / \mathrm{NADH}$ ratio is associated with increased SIRT1 protein levels in the livers of fasted rats (Rodgers et al. 2005). Fructose-induced gluconeogenesis can be suppressed by inhibition of the electron transport chain. This may be due to a decrease in $\mathrm{NAD}^{+}$, NADH ratio that occurs in parallel (Pryor et al. 1987), but the role of SIRT1 in the hepatic response to fructose has yet to be examined.

In this study, we demonstrate that fructose induces hepatic gluconeogenesis and lipogenic gene expression through a SIRT1-dependent mechanism. This occurs through a complex I-mediated increase in $\mathrm{NAD}^{+} / \mathrm{NADH}$ ratio. This study indicates that SIRT1 activators may cause adverse metabolic consequences if used as a therapeutic strategy for T2DM.

\section{Materials and Methods}

\section{Materials}

Primary hepatocytes isolated from male Sprague-Dawley rats were purchased from $3 \mathrm{H}$ Biomedical (Uppsala, Sweden). SIRT1 activator 3 (Catalogue \#; 10009797) and SRT1720 (Catalogue \#; CAY10559) were obtained from Cayman Chemical, Ann Arbor, MI, USA. EX-527 (6-chloro-2,3,4,9tetra-hydro-1-H-carbazole-1-carboxamide) was obtained from Alexis Biochemical, Nottingham, UK. Rotenone was from CalBiochem, Nottingham, UK. All other materials were from Sigma, unless otherwise stated.

\section{Cell culture}

Rat H4IIEC3 hepatoma cells were cultured in DMEM containing $5 \mathrm{mM}$ glucose, non-essential amino acids, and $10 \%$ (v/v) FCS. Primary hepatocytes were suspended in William's E Glutamax media (Invitrogen) and cultured for $4 \mathrm{~h}$ prior to treatment, to allow adherence to collagen-coated cell culture plates (Invitrogen). Cells were incubated with fructose $(5 \mathrm{mM})$, lactate $(20 \mathrm{mM})$, pyruvate $(2 \mathrm{mM})$, or with SIRT1 activators for $6 \mathrm{~h}$ in glucose-free Earle's Balanced Salt Solution (EBSS; $0 \cdot 264 \mathrm{~g} / 1 \quad \mathrm{CaCl}_{2} \cdot 2 \mathrm{H}_{2} \mathrm{O} ; 0.4 \mathrm{~g} / 1 \mathrm{KCl}$; $0 \cdot 2 \mathrm{~g} / 1 \quad \mathrm{MgSO}_{4} \cdot 7 \mathrm{H}_{2} \mathrm{O} ; 2 \cdot 2 \mathrm{~g} / 1 \quad \mathrm{NaHCO}_{3} ; \quad 0 \cdot 158 \mathrm{~g} / 1$ $\mathrm{NaH}_{2} \mathrm{PO}_{4} \cdot 2 \mathrm{H}_{2} \mathrm{O}, \mathrm{pH} 7 \cdot 4$ ), or co-incubated with EX-527 $(5-10 \mu \mathrm{M})$ and fructose $(5 \mathrm{mM})$ for $6 \mathrm{~h}$ in glucose-free EBSS. Pretreatment with nicotinamide and rotenone was for $24 \mathrm{~h}$ in DMEM containing $5 \mathrm{mM}$ glucose prior to fructose incubations. For cholesterol measurements, cells were incubated with fructose $(5 \mathrm{mM})$ or co-incubated with fructose plus nicotinamide $(2 \mathrm{mM})$ or rotenone $(50 \mathrm{nM})$ for $24 \mathrm{~h}$ in DMEM containing $5 \mathrm{mM}$ glucose. For rotenone and SIRT1 activator 3 experiments, H4IIEC3 cells were pretreated with rotenone $(1 \mathrm{~h} ; 50 \mathrm{nM})$, prior to $6 \mathrm{~h}$ incubation with fructose $(5 \mathrm{mM})$, or co-incubated with SIRT1 activator $3(60 \mu \mathrm{M})$.

\section{Glucose measurements}

Glucose was measured using a colorimetric glucose oxidase assay based on the method described by Hugget and Nixon (Bergmeyer 1963). Glucose levels are expressed as nmol/ $2 \cdot 5 \times 10^{5}$ cells $($ H4IIEC3) or $\mathrm{mM}$ (primary hepatocytes).

\section{PEPCK activity}

PEPCK activity was assayed as described previously (Caton et al. 2009) using a three-sequential reaction process based on the stoichiometric transformation of oxaloacetate (OAA), via phosphoenolpyruvate (PEP) into ATP. PEPCK activity is expressed as nM PEP produced per mg protein.

\section{Quantitative RT-PCR}

Expression of all genes was measured using qRT-PCR, according to the procedure described previously (Douthwaite et al. 2003). Relative mRNA levels were determined by standard curve methodology normalized against $18 \mathrm{~S}$ ribosomal control RNA (Applied Biosystems, Warrington, UK). Changes in gene expression are represented as fold change relative to 1 , where control equals 1 .

\section{Western blotting}

Solubilized protein samples $(10 \mu \mathrm{g}$; measured and equalized in each fraction using the Bio-Rad RC-DC protein assay; Bio-Rad) were separated by SDS-PAGE and transferred onto nitrocellulose Hybond membrane or PVDF membrane (GE Healthcare, Amersham, UK). Membranes were blocked with $3 \%(\mathrm{w} / \mathrm{v})$ milk protein in Tris-buffered saline containing $0 \cdot 1 \%$ Tween-20, and then incubated overnight with primary antibody. Antibodies used in this study were ovalbuminconjugated mouse monoclonal anti-SIRT1 IgG (1:1000 dilution; clone 2G1/F7; Upstate Biotech, Billerica, NY, USA), anti-phospho( $\left.\mathrm{Thr}^{183} / \mathrm{Tyr}^{185}\right)$ SAPK/JNK, anti-total JNK (Cell Signaling Technologies, Danvers, MA, USA). Detection of bands was achieved by using the chemiluminescent substrate SuperSignal West Pico (Pierce, Rockford, IL, USA). 
Blots are representative of three separate blots. Densitometry was determined using Image J software (National Institutes of Health, Bethesda, Maryland, USA). Reference protein measurements were made with mouse monoclonal anti- $\beta$-actin (clone AC-15) primary antibody in a $3 \%(\mathrm{w} / \mathrm{v}) \mathrm{milk} / \mathrm{TNT}$ solution (data not shown).

\section{SIRT1 activity}

SIRT1 activity was assayed in nuclear fractions isolated from primary hepatocytes or H4IIEC3 cells using a two-step fluorometric technique based on deacetylation of lysine in the substrate Boc-Lys(Ac)-AMC (Bachem, St Helens, UK), followed by trypsin treatment to release fluorescent 7-amino-4-methyl coumarin (AMC; Ishdorj et al. 2008). Nuclear isolation from cell samples was carried out by following the published methods (Kain et al. 2000). Protein content was measured and equalized in each fraction using the Bio-Rad RC-DC protein assay. Trichostatin A (TSA) as a class I and II histone deacetylase (HDAC) inhibitor and nicotinamide or EX-527 as SIRT1 inhibitors were used to confer specificity for SIRT1 activity as opposed to general HDAC or nuclear sirtuin activity. SIRT1 activity is expressed as AMC produced ( $\mu$ moles) per mg protein.

\section{$N A D^{+} / N A D H$ ratio and $A T P$ levels}

ATP levels and $\mathrm{NAD}^{+} / \mathrm{NADH}$ ratio were measured according to the published methods (San et al. 2002, Moynihan et al. 2005). ATP levels are expressed as relative luminescence units. ATP levels and $\mathrm{NAD}^{+} / \mathrm{NADH}$ ratio are represented as fold change relative to 1 , where control equals 1 .

\section{Intracellular cholesterol assays}

Cells $\left(1 \cdot 2 \times 10^{6}\right)$ were washed twice in $1 \mathrm{ml}$ ice-cold PBS and scraped into $1 \mathrm{ml}$ ice-cold extraction buffer $(320 \mathrm{mM}$ sucrose, $1 \mathrm{mM}$ EDTA, $1 \mathrm{mg} / \mathrm{ml} \mathrm{BSA}$, and $10 \mathrm{mM}$ Tris-HCl, $\mathrm{pH} 7 \cdot 1$; $1 \%$ Triton-X). Harvested cells were centrifuged at $1000 \mathrm{~g}$ for $10 \mathrm{~min}$ at $4{ }^{\circ} \mathrm{C}$ to produce a cell pellet, which was resuspended in $1 \mathrm{ml}$ extraction buffer. Cell lysate samples or supernatants $(150 \mu \mathrm{l})$ were added to reaction buffer $(50 \mu \mathrm{l})$ containing $0 \cdot 1 \mathrm{M}$ potassium phosphate $(\mathrm{pH} 7 \cdot 4), 50 \mathrm{mM} \mathrm{NaCl}, 5 \mathrm{mM}$ cholic acid, $1 \mathrm{U} / \mathrm{ml}$ cholesterol oxidase, $1 \mathrm{U} / \mathrm{ml}$ cholesterol esterase, $1 \mathrm{U} / \mathrm{ml} \mathrm{HRP}$, and $150 \mu \mathrm{M}$ Amplex Red reagent, mixed vigorously and incubated at $37^{\circ} \mathrm{C}$ for $30 \mathrm{~min}$. The assay is based on a two-sequential enzymatic reaction process. Initially, cholesterol esters are hydrolyzed by cholesterol esterase into cholesterol. Cholesterol is then oxidized by
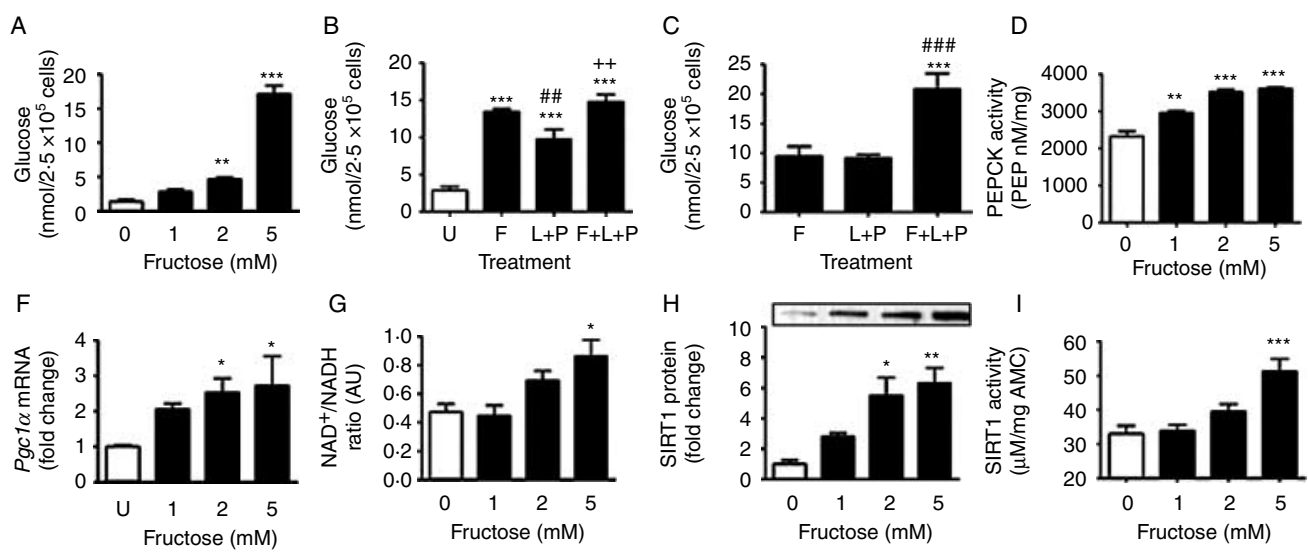

G

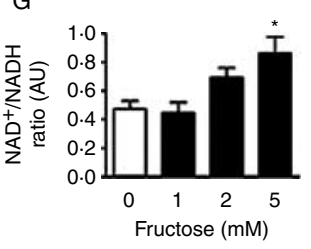

E

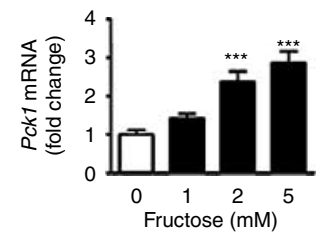

$J$
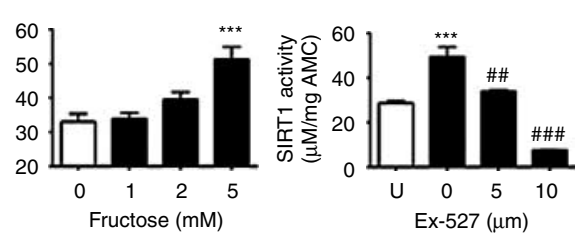
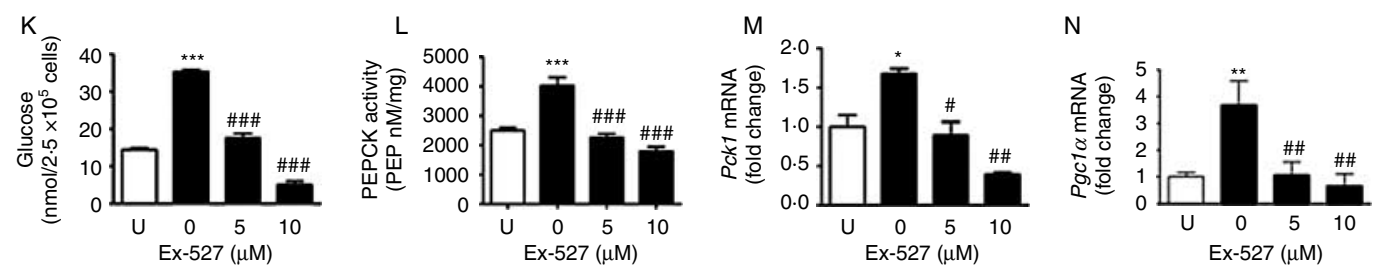

Figure $1 \mathrm{H} 411 \mathrm{EC} 3$ cells were incubated for $6 \mathrm{~h}$ with fructose $(1-5 \mathrm{mM})$ in glucose-free EBSS (A, D-G; $n=6)$; (A) glucose production, (D) PEPCK activity, (E) Pck1 and (F) Pgc1 $\alpha$ mRNA levels, (G) cellular NAD ${ }^{+} / \mathrm{NADH}_{\text {ratio, }}(\mathrm{H})$ SIRT1 protein levels (representative blot; $n=3$ ), (I) SIRT1 activity (co-incubated with TSA $(3 \mu \mathrm{g} / \mathrm{ml}))$. Co-incubation of EX-527 $(5-10 \mu \mathrm{M})$ and fructose $(5 \mathrm{mM} ; n=6)$ for $6 \mathrm{~h}$ inhibits fructose-induced increases in (J) SIRT1 activity, (K) glucose production, (L), PEPCK activity, (M) Pck1 and (N) Pgc1 $\alpha$ mRNA levels. Alternatively, H411EC3 cells were incubated for 6 or $24 \mathrm{~h}$ with fructose $(5 \mathrm{mM} ; \mathrm{F})$, pyruvate $(2 \mathrm{mM} ; \mathrm{P})$, and lactate $(20 \mathrm{mM} ; \mathrm{L})$ in glucose-free EBSS (B and $\mathrm{C} ; n=6$ ). Data are expressed as mean \pm s.E.M. ${ }^{*} P<0 \cdot 05,{ }^{* *} P<0 \cdot 01,{ }^{* * *} P<0 \cdot 001$ versus untreated control $(\mathrm{U}) ;{ }^{*} P<0 \cdot 05$, ${ }^{\# \#} P<0 \cdot 01,{ }^{\# \#} P<0 \cdot 001$ versus fructose alone; ${ }^{+}+P<0 \cdot 01$ versus $P$ and $L$ alone. 
cholesterol oxidase to produce $\mathrm{H}_{2} \mathrm{O}_{2}$. In the presence of $\mathrm{HRP}$, Amplex Red reacts with $\mathrm{H}_{2} \mathrm{O}_{2}$ with a 1:1 stoichiometry to produce resorufin, a fluorescent compound (Ex: $560 \mathrm{~nm}$; Em $590 \mathrm{~nm}$ ) measured using a Cytofluor II multiwell plate reader (PerSeptive Biosystems, Framingham, MA, USA).

\section{Statistical analysis}

Results are expressed as mean \pm s.E.M. Statistical differences were determined using StatView (SAS Institute, Inc., Cary, NC, USA) with either a two-tailed unpaired $t$-test or a one-way ANOVA followed by a Fisher's post-hoc test, where appropriate. A $P$ value of 0.05 was considered significant.

\section{Results}

Fructose induces gluconeogenesis through a SIRT1-dependent mechanism

H4IIEC3 cells were incubated with fructose at concentrations of 1-5 mM. These concentrations were chosen because levels of fructose present in the hepatic portal vein in humans and rats following consumption of a fructose-rich meal are estimated to be $\sim 1 \cdot 1-2 \cdot 2 \mathrm{mM}$ (Mayes 1993, Pagliassotti et al. 2003). Incubation of H4IIEC3 cells with fructose induced increases in glucose production (Fig. 1A). Fructose $(5 \mathrm{mM})$ alone induced glucose production to a greater extent than pyruvate $(2 \mathrm{mM})$ and lactate $(20 \mathrm{mM})$ over $6 \mathrm{~h}$, while co-incubation with fructose, pyruvate, and lactate did not further increase glucose production compared with fructose alone (Fig. 1B). Interestingly, over $24 \mathrm{~h}$, co-incubation with fructose, lactate, and pyruvate induced a twofold increase in glucose production compared with fructose alone (Fig. 1C). Fructose (alone)-induced increases in glucose production occurred in parallel with increased PEPCK activity (Fig. 1D), and mRNA levels of Pck1 (Fig. 1E) and Pgc1 $\alpha$ (Fig. 1F). SIRT1, a nuclear $\mathrm{NAD}^{+}$-dependent protein deacetylase enzyme (Landry et al. 2000), has been shown to induce gluconeogenic gene expression (Rodgers et al. 2005, Rodgers \& Puigserver 2007). Consistent with fructose-induced gluconeogenesis being mediated through SIRT1, fructose increased $\mathrm{NAD}^{+} / \mathrm{NADH}$ ratio (Fig. $1 \mathrm{G}$ ), SIRT1 protein level (Fig. 1H), and nuclear HDAC activity (Fig. 1I). HDAC activity was not inhibited by TSA, an inhibitor of class I and II HDAC that does not affect class III HDACs such as SIRT1 (Marmorstein 2004, Li et al. 2007). This indicated that the observed increase in HDAC occurs through increased activity of the nuclear sirtuins: SIRT1, 6, or 7 (Michan \& Sinclair 2007). The effect of fructose on nuclear sirtuin activity was also inhibited by the SIRT1 inhibitors EX-527, a specific SIRT1 inhibitor (Fig. 1J), and nicotinamide (Supplementary Figure 1A, see section on supplementary data given at the end of this article) at similar concentrations to those used in previous studies of SIRT1 activation (Napper et al. 2005, Rodgers et al. 2005). This indicated that the fructose-induced increase in nuclear sirtuin activity occurred as a result of increased SIRT1 activity.

To establish whether fructose-induced gluconeogenesis is dependent on SIRT1, hepatocytes were co-incubated with EX-527 and fructose. EX-527 inhibited fructose-induced increases in hepatic glucose production (Fig. 1K), PEPCK activity (Fig. 1L) as well as Pck1 (Fig. 1M) and Pgc1 $1 \alpha$ (Fig. 1N) mRNA levels. Fructose-induced gluconeogenesis was also inhibited by nicotinamide (Supplementary Figure 1B-E). However, pretreatment with TSA had no effect on fructoseinduced gluconeogenesis (Supplementary Figure 1F and G).

Previous studies have reported that fructose can induce an acute stress response in hepatocytes and liver through
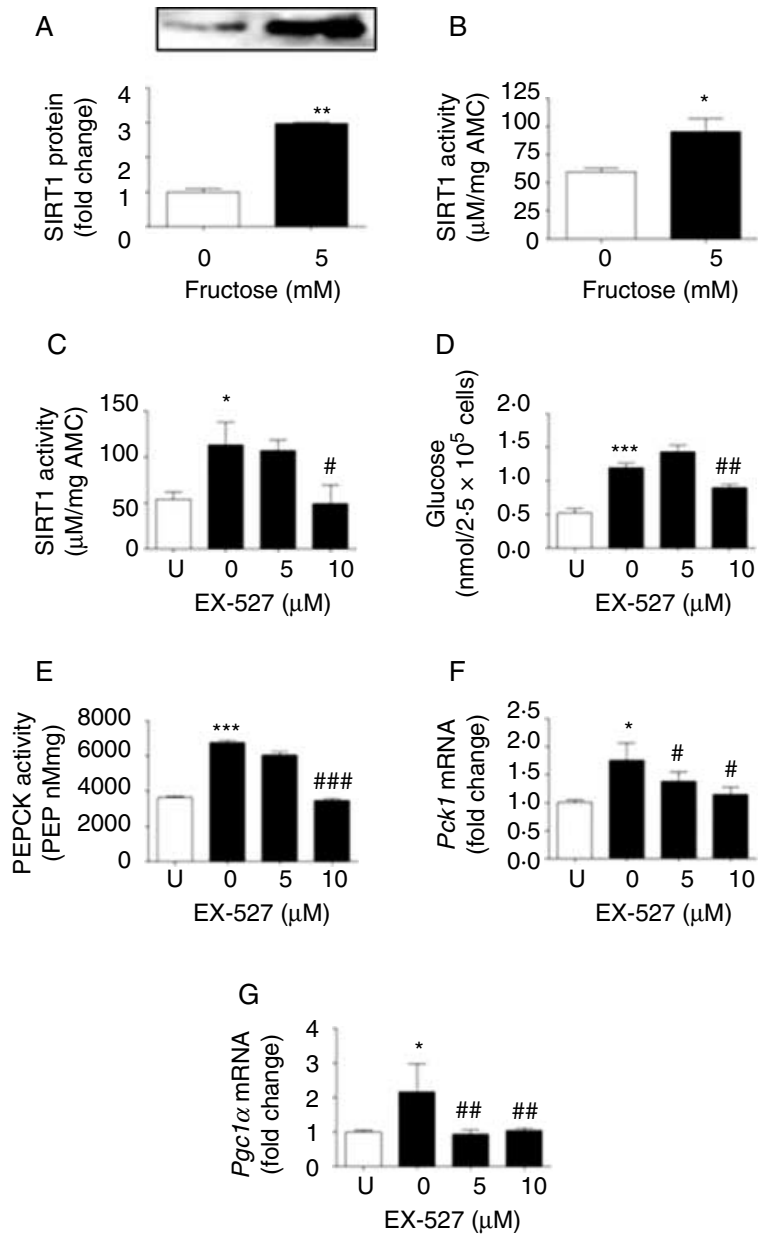

Figure 2 Primary hepatocytes isolated from male Sprague-Dawley rats were incubated for $6 \mathrm{~h}$ with fructose $(5 \mathrm{mM})$ in glucose-free EBSS (A and B); (A) SIRT1 protein levels (representative blot; $n=3$ ), (B) SIRT1 activity $(n=6)$. Co-incubation of EX-527 $(5-10 \mu \mathrm{M})$ with fructose ( $5 \mathrm{mM} ; n=6)$ for $6 \mathrm{~h}$ inhibits fructose-induced increases in (C) SIRT1 activity, (D) glucose production, (E) PEPCK activity,

(F) PCk1 and (G) Pgc1 $\alpha$ mRNA levels. Data are expressed as mean \pm S.E.M. $* P<0 \cdot 05, * * P<0 \cdot 01, * * * P<0 \cdot 001$ versus untreated control (U); ${ }^{\#} P<0 \cdot 05,{ }^{\# \#} P<0 \cdot 01,{ }^{\# \#} P<0 \cdot 001$ versus fructose alone. 
activation of c-JUN N-terminal kinase (JNK; Kelley et al. 2004, Wei \& Pagliassotti 2004, Wei et al. 2005). In agreement, we report protein expression of phospho( $\mathrm{Thr}^{183} / \mathrm{Tyr}^{185}$ )SAPK/JNK, indicating JNK activation, after 30-min fructose incubation. Similarly, SIRT1 levels were high following $30-\mathrm{min}$ fructose incubation. However, phospho( $\mathrm{Thr}^{183} / \mathrm{Tyr}^{185}$ ) SAPK/JNK significantly decreased between $30 \mathrm{~min}$ and $1 \mathrm{~h}$, becoming undetectable at 3-6 h, indicating that JNK activation occurs as an acute response to fructose and is not sustained over longer periods (Supplementary Figure 2A, see section on supplementary data given at the end of this article). In contrast, SIRT1 protein levels decreased significantly between $30 \mathrm{~min}$ and $1 \mathrm{~h}$, increased slightly between 1 and $3 \mathrm{~h}$, before increasing markedly between 3 and $6 \mathrm{~h}$ (Supplementary Figure 2A). This is suggestive of an initial acute fructoseinduced SIRT1 response, perhaps mediated by JNK activation, followed by a longer-term, JNK-independent, effect over $6 \mathrm{~h}$. Interestingly, only at $6 \mathrm{~h}$ were significant increases in PEPCK activity observed, which corresponded with changes in hepatic glucose production being markedly increased at $6 \mathrm{~h}$, compared with $1 \mathrm{~h}$ (Supplementary Figure 2B).

To further evaluate physiological relevance, results were confirmed in primary rat hepatocytes. Consistent with the findings in H4IIEC3 cells, incubation of primary hepatocytes with fructose $(5 \mathrm{mM})$ increased the levels of SIRT1 protein (Fig. 2A) and activity (Fig. 2B), while fructose-induced increases in SIRT1 activity were suppressed by EX-527 (Fig. 2C). In primary hepatocytes, fructose also increased glucose production (Fig. 2D), PEPCK activity (Fig. 2E), and mRNA levels of Pck1 and Pgc1 $\alpha$ (Fig. $2 \mathrm{~F}$ and G). These changes were inhibited by EX-527, further indicating that fructose induces gluconeogenesis through a SIRT1mediated mechanism. Observed changes in glucose production, PEPCK and SIRT1 activities were markedly higher in primary hepatocytes than in H4IIEC3 cells, likely reflecting the increased metabolic activity of these hepatocytes.

\section{SIRT1 activators induce gluconeogenesis}

To establish the role of SIRT1 in the induction of gluconeogenesis, we analyzed the ability of a potent SIRT1 activator, SIRT1 activator 3 (Nayagam et al. 2006), to stimulate gluconeogenesis in H4IIEC3 cells and primary hepatocytes. SIRT1 activator 3 increased SIRT1 activity in the presence of TSA (Fig. 3A and B). It also raised PEPCK activity (Fig. 3C and D), mRNA levels of Pck1 (Fig. 3E and F) and $P g c 1 \alpha$ (Fig. $3 \mathrm{G}$ and $\mathrm{H}$ ) as well as glucose production (Fig. 3I and J).

SRT1720 has been described as a small molecule activator of SIRT1 (Milne et al. 2007), although a recent study has suggested that this compound is not a direct activator of SIRT1 and may act on multiple targets (Pacholec et al. 2010). However, since SRT1720 is currently under investigation as a therapy for T2DM, we assessed whether this compound could also induce gluconeogenesis. Incubation of H4IIEC3 cells and primary hepatocytes with SRT1720 increased SIRT1 activity in the presence of TSA (Fig. 4A and B), as well as increasing PEPCK activity (Fig. 4C and D), mRNA levels of Pck1 (Fig. 4E and F) and Pgc1 $\alpha$ (Fig. 4G and H), and elevating glucose production (Fig. 4I and J).

Taken together, these data show that induction of hepatic SIRT1 can induce gluconeogenesis, and that fructose induces gluconeogenesis through a SIRT1-mediated mechanism.

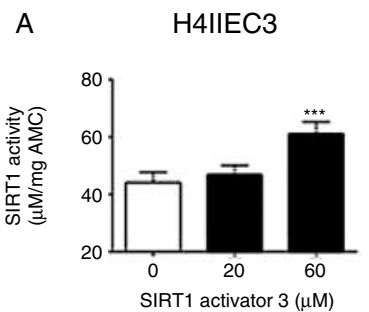

\section{B Primary hepatocytes}
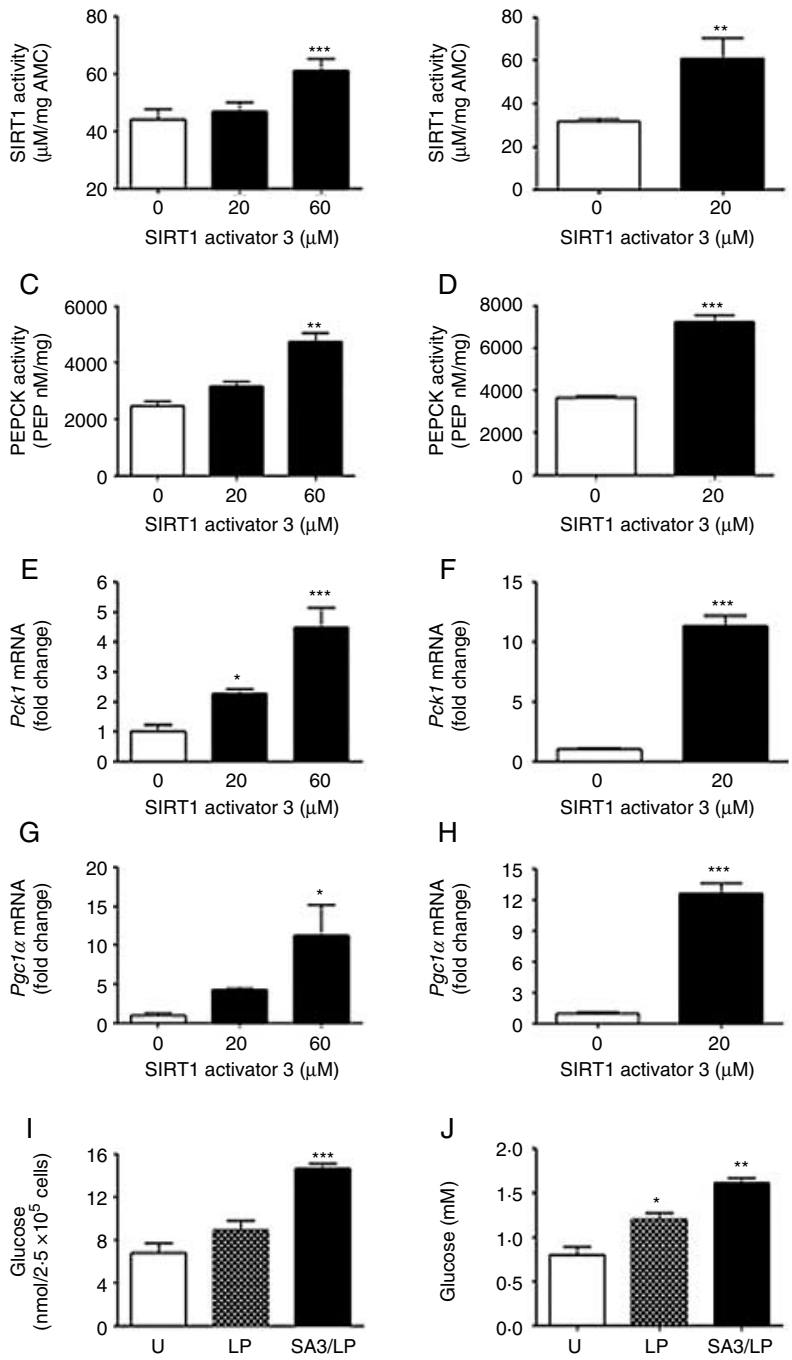

Figure $3 \mathrm{H} 411 \mathrm{EC} 3$ cells and primary hepatocytes were incubated for $6 \mathrm{~h}$ with SIRT1 activator $3(20-60 \mu \mathrm{M})$ in glucose-free EBSS $(n=6)$; (A and B) SIRT1 activity, (C and D) PEPCK activity, (E and F) $P c k 1$ and (G and $\mathrm{H}) P g c 1 \alpha$ mRNA levels. For glucose measurements, (I and J) H411EC3 and primary hepatocytes were incubated for $6 \mathrm{~h}$ with $10 \mathrm{mM}$ lactate and $2 \mathrm{mM}$ pyruvate (LP) with or without SIRT1 activator $3(20 \mu \mathrm{M})$. Data are expressed as mean \pm S.E.M. $* P<0 \cdot 05, * * P<0 \cdot 01, * * * P<0 \cdot 001$ versus untreated control $(0)$. 


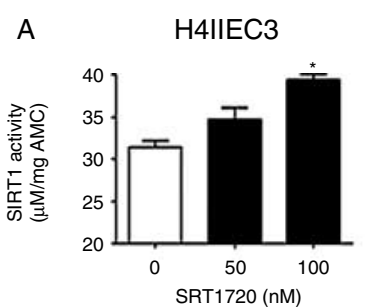

\section{B Primary hepatocytes}
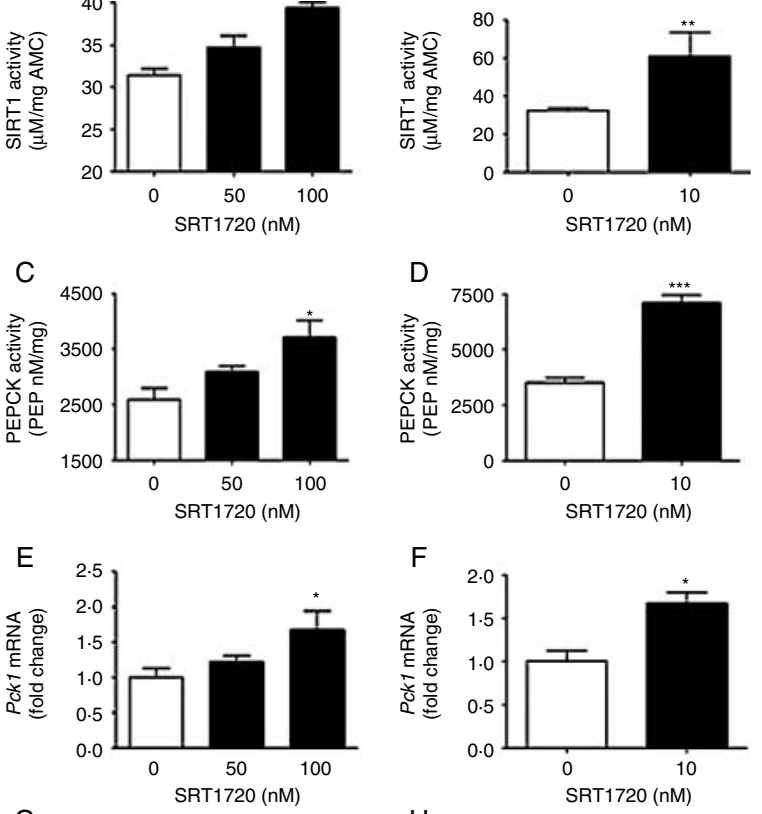

G
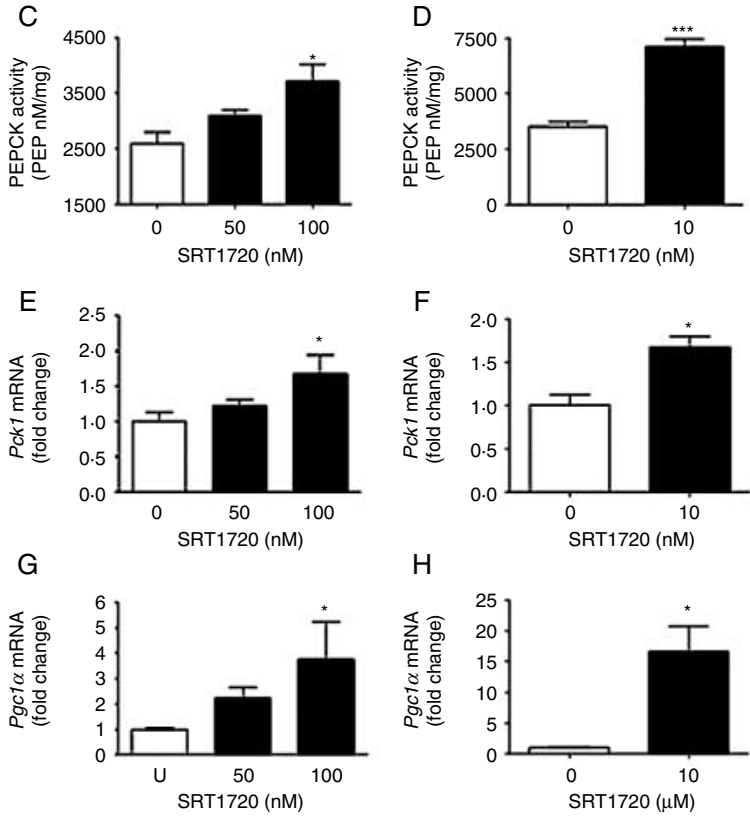

$\mathrm{F}$

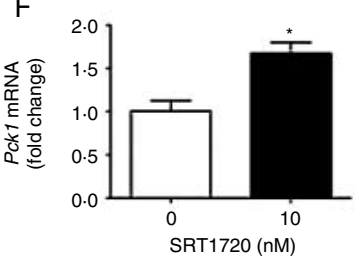

$\mathrm{H}$
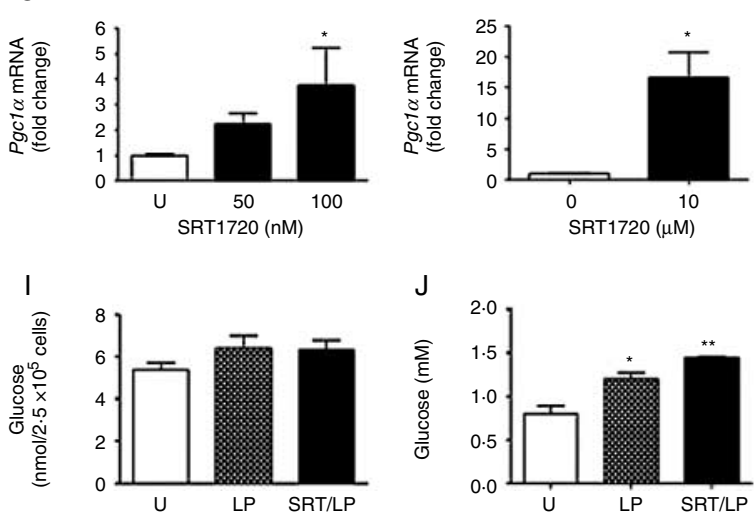

Figure $4 \mathrm{H} 411 \mathrm{EC} 3$ cells and primary hepatocytes were incubated for $6 \mathrm{~h}$ with SRT1720 (50-100 and $10 \mathrm{nM}$ respectively) in glucosefree EBSS $(n=6)$; (A and B) SIRT1 activity, (C and D) PEPCK activity, (E and F) PCk1 and (G and H) Pgc1 $\alpha$ mRNA levels. For glucose measurements, (I and J) H411EC3 and primary hepatocytes were incubated for $6 \mathrm{~h}$ with $10 \mathrm{mM}$ lactate and $2 \mathrm{mM}$ pyruvate (LP) with or without SRT1720 (100 or $10 \mathrm{nM}$ respectively). Data are expressed as mean \pm s.E.M. ${ }^{*} P<0 \cdot 05,{ }^{* *} P<0 \cdot 01,{ }^{* * *} P<0 \cdot 001$ versus untreated control $(0)$.

\section{Mitochondrial complex I regulates SIRT1-dependent response to fructose}

Activation of complex I of the mitochondrial electron transport chain increases $\mathrm{NAD}^{+} / \mathrm{NADH}$ ratio through increased $\mathrm{NAD}^{+}$production as well as increasing ATP production from ADP (Voet \& Voet 1994). Fructose induced gluconeogenesis through a SIRT1-mediated mechanism in parallel with increasing $\mathrm{NAD}^{+} / \mathrm{NADH}$ ratio (Figs 1 and 2)

and ATP levels at $6 \mathrm{~h}$ (Supplementary Figure 3A, see section on supplementary data given at the end of this article). Therefore, we tested whether changes in SIRT1 resulted from increased complex I activity by using rotenone, a potent complex I inhibitor. Rotenone inhibited fructose-induced increases in $\mathrm{NAD}^{+} / \mathrm{NADH}$ ratio (Fig. 5A), ATP levels (Fig. 5B), SIRT1 protein (Fig. 5C), and SIRT1 activity (Fig. 5D). Rotenone also inhibited fructose-induced increases in hepatocyte glucose production (Fig. 5E), PEPCK activity (Fig. 5F), and mRNA levels of Pck1 (Fig. 5G) and Pgc1 $\alpha$ (Fig. $5 \mathrm{H}$ ). These results suggest that the changes in $\mathrm{NAD}^{+}$/ $\mathrm{NADH}$ ratio and SIRT1 in response to fructose occur through increased activity of complex I of the mitochondrial electron transport chain. Consistent with observations of increased SIRT1 expression and activity at $6 \mathrm{~h}$, time course studies indicated that $\mathrm{NAD}^{+} / \mathrm{NADH}$ ratios were only increased with $6 \mathrm{~h}$ fructose incubation and were unchanged at 1 and $3 \mathrm{~h}$ (Supplementary Figure 3B).

To further elucidate the role of complex I in fructoseinduced SIRT1-mediated gluconeogenesis, we investigated whether the inhibitory effects of rotenone could be overcome by SIRT1 activator 3. Pretreatment with rotenone inhibited fructose-induced hepatic glucose production to basal level. Activation of SIRT1 by incubation of fructose with SIRT1 activator 3 after pretreatment with rotenone partially countered the effect of rotenone, as hepatic glucose production increased to $60 \%$ of the levels achieved by incubation with fructose alone (Fig. 5I). This suggests that while the electron transport chain exerts some SIRT1-independent flux control over gluconeogenesis in response to fructose, $\sim 60 \%$ of the fructose-mediated induction of hepatic glucose production observed in these experiments occurs through SIRT1.

Taken together, these data show that fructose-induced increases in SIRT1 occur through activation of complex I of the electron transport chain causing increased $\mathrm{NAD}^{+}$/ NADH and ATP levels, leading to increased SIRT1 activation and induction of gluconeogenesis.

Fructose induces lipogenic gene expression through a SIRT1-mediated mechanism

To determine whether fructose also induces de novo lipogenesis and cholesterol synthesis through a SIRT1dependent mechanism, we measured alterations in gene expression of acetyl-coA carboxylase (Acc) and 3-hydroxy-3methylglutaryl coenzyme A reductase $(\mathrm{Hmgcr})$, the ratelimiting enzymes for lipogenesis and cholesterol synthesis (Hobbs et al. 1990, Rodgers \& Puigserver 2007). The response of primary hepatocytes to SIRT1 activators and fructose alone or co-incubated with EX-527 was evaluated. In addition, we measured the impact of SIRT1 activators on gene expression of two key regulators of lipogenic gene expression; Pgc1 $\beta$ and sterol regulatory element-binding protein 1c (Srebp1c). 
A
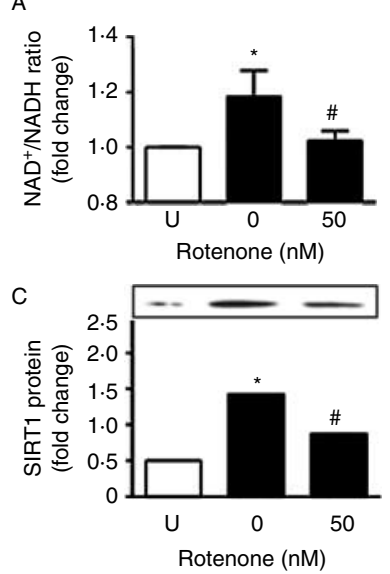

E

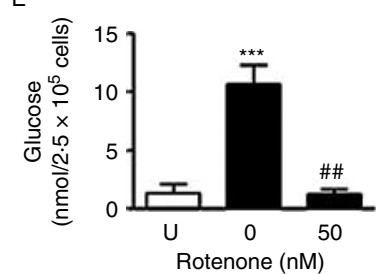

G

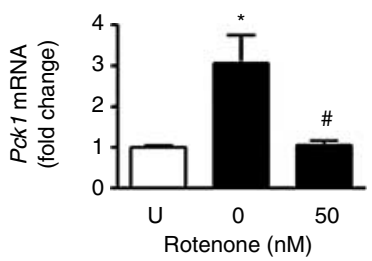

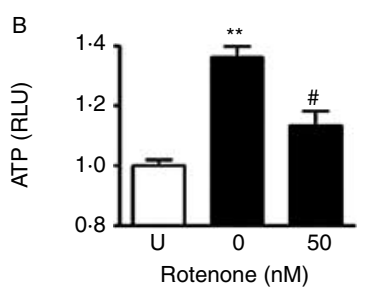

D
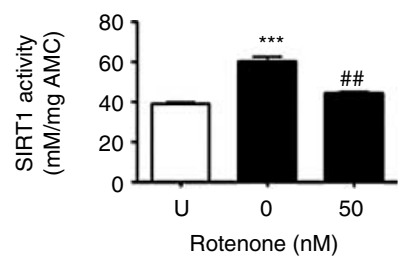

$\mathrm{F}$

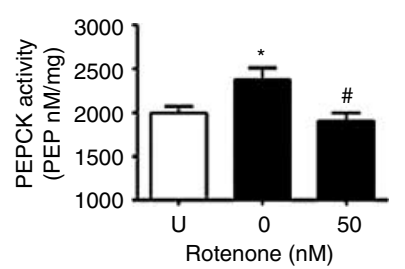

$\mathrm{H}$
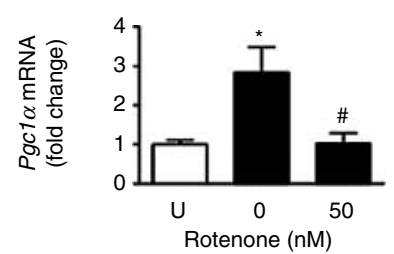

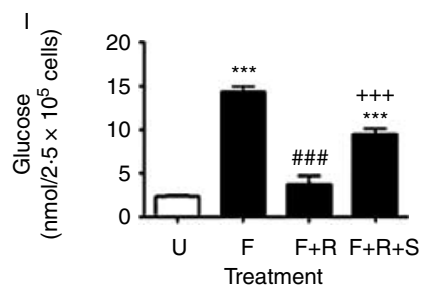

Figure 5 Pretreatment of H4IIEC3 cells for $24 \mathrm{~h}$ with rotenone $(50 \mathrm{nM})$ inhibited fructose-induced $(6 \mathrm{~h} ; 5 \mathrm{mM} ; n=6)$ increases in (A) cellular $\mathrm{NAD}^{+} / \mathrm{NADH}$ ratio, (B) cellular ATP levels, (C) SIRT1 protein levels (representative blot; $n=3$ ), (D) SIRT1 activity, (E) glucose production, (F) PEPCK activity, (G) Pck1 and (H) Pgc1 $1 \alpha$ mRNA levels. (I) H4IIEC3 cells were pretreated with rotenone $(50 \mathrm{nM}$; R) for $1 \mathrm{~h}$, prior to $5 \mathrm{~h}$ incubation with fructose $(5 \mathrm{mM} ; \mathrm{F})$ or co-incubation with fructose $(5 \mathrm{mM})$ and SIRT1 activator 3 $(60 \mu \mathrm{M} ; \mathrm{S})$. Data are expressed as mean \pm S.E.M. ${ }^{*} P<0 \cdot 05,{ }^{* *} P<0 \cdot 01$, ${ }_{* * *} P<0 \cdot 001$ versus untreated control $(U) ;{ }^{\#} P<0 \cdot 05,{ }^{\#} P<0 \cdot 01$,

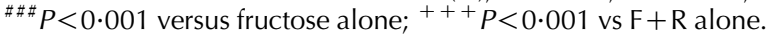

Fructose induced gene expression levels of Hmgcr and Acc. These responses were inhibited by EX-527 (Fig. 6A and E). $\mathrm{Hmgcr}$ and $\mathrm{Acc}$ gene expression was also increased by both SIRT1 activator 3 (Fig. 6B and F) and SRT1720 (Fig. 6C and $\mathrm{G})$. In addition, fructose-induced increases in $\mathrm{Hmgcr}$ and $\mathrm{Acc}$ were inhibited by rotenone (Fig. 6D and $\mathrm{H}$ ), further

highlighting the importance of complex I activity for induction of SIRT1 by fructose. Fructose also induced intracellular cholesterol production over $24 \mathrm{~h}$, an effect that was inhibited by nicotinamide and rotenone (Fig. 6I-K). Moreover, SIRT1 activator 3 and SRT1720 induced gene expression of hepatic Pgc1 $\beta$ (Fig. 6L and M) and Srebp $1 c$ (Fig. 6N and O) in primary hepatocytes.

Taken together, these data indicate that fructose induces Hmgcr and Acc gene expression through a SIRT1-dependent mechanism, and that these responses may occur through SIRT1-mediated induction of PGC1 $\beta$ and SREBP1c.

\section{Discussion}

Previous studies have described the function of hepatic SIRT1 in the induction of gluconeogenesis, focusing on its role in hepatic glucose production in response to fasting, and in glucose-starved cultured hepatocytes (Rodgers et al. 2005, Rodgers \& Puigserver 2007). In this study, we show that fructose as a nutrient substrate, at concentrations similar to estimates for the hepatic portal vein, stimulates gluconeogenesis via SIRT1. This indicates that activation of hepatic SIRT1 could contribute to the metabolic abnormalities observed following excess dietary fructose consumption. This is significant since consumption of a fructose-rich diet impairs glucose and lipid homeostasis leading to a metabolic syndrome-like state and has been associated with the development of obesity and T2DM (Bray et al. 2004, Gaby 2005, Johnson et al. 2007). While the effect of fructose feeding on hepatic SIRT1 has yet to be directly examined in vivo, SIRT1 is reportedly induced in the hearts of fructose-fed rats (Pillai et al. 2008).

Other animal studies support the idea that dysregulation of hepatic SIRT1 could lead to hyperglycemia through induction of abnormally elevated hepatic gluconeogenesis. RNA interference and antisense oligonucleotide-mediated knockdown of hepatic SIRT1 resulted in the correction of hyperglycemia in two different rodent models of T2DM (Rodgers \& Puigserver 2007, Erion et al. 2009). SIRT1 is reported to induce gluconeogenesis through removal of STAT3-dependent inhibition of gluconeogenesis (Nie et al. 2009) and by deacetylation-mediated facilitation of FOXO1 nuclear retention (Frescas et al. 2005), indicating that inappropriate activation of SIRT1 can contribute to hyperglycemia. Interestingly, SIRT1 null mice that survive to adulthood display a phenotype that includes low blood glucose (Chen \& Guarente 2007), indicating inability to induce gluconeogenesis.

Others have shown that SIRT1 activators increase Pck1 gene expression (Feige et al. 2008). Chronic treatment of ob/ob mice fed a high-fat diet with the putative SIRT1 activator, SRT1720 (30 mg/kg), led to increased food intake and body weight (Pacholec et al. 2010), and SRT1720 did not lower plasma glucose or improve mitochondrial capacity in this study. 


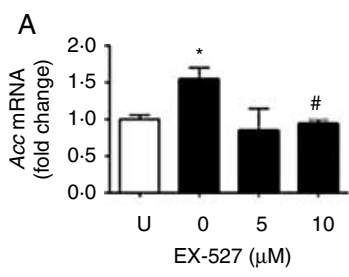

E
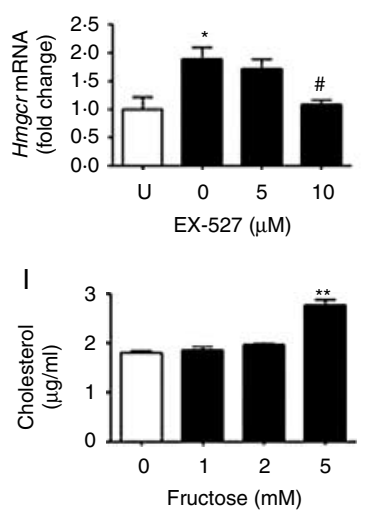

B

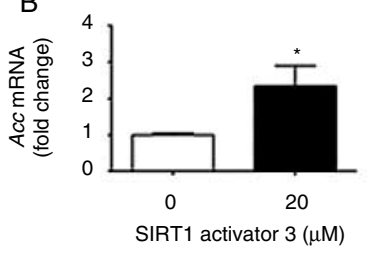

F
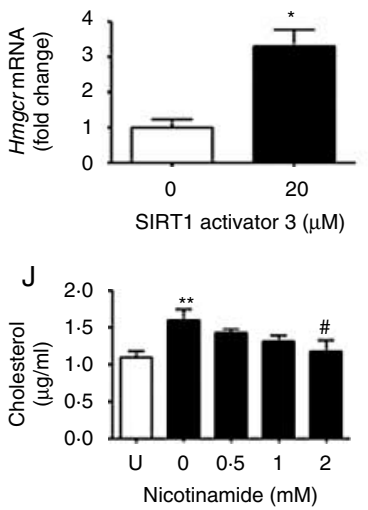

N
C

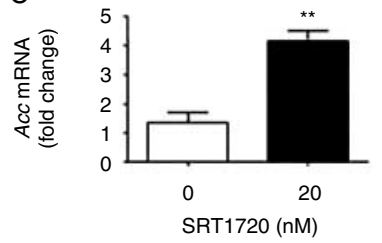

G

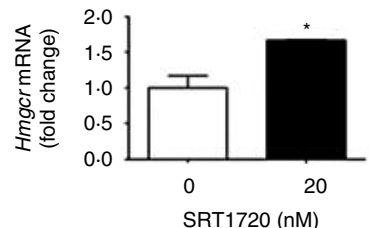

K

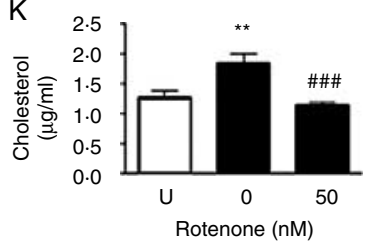

D

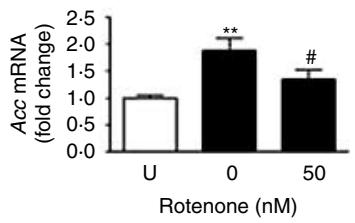

$\mathrm{H}$
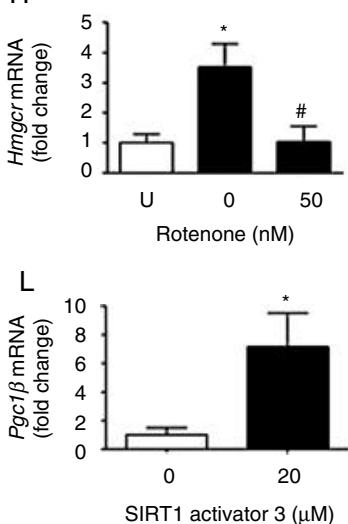

M

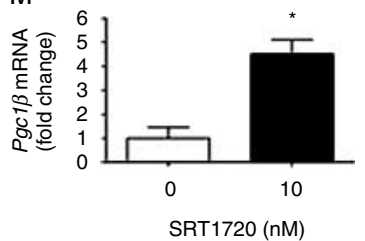

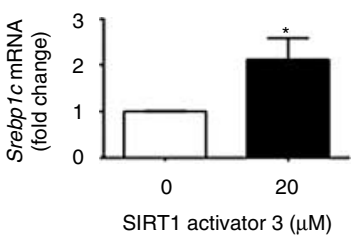

$\mathrm{O}$

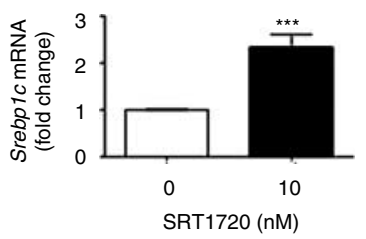

Figure 6 Primary hepatocytes were co-incubated for $6 \mathrm{~h}$ with either EX-527 (5-10 $\mu \mathrm{M})$ in combination with fructose ( $5 \mathrm{mM})$, or for $6 \mathrm{~h}$ with SIRT1 activator $3(20 \mu \mathrm{M})$ or SRT1720 $(10 \mathrm{nM})$, without fructose, in glucose-free EBSS $(n=6)$, and mRNA levels for Acc (A-C), Hmgcr $(\mathrm{E}-\mathrm{G}), \operatorname{Pgc} 1 \beta(\mathrm{L}$ and $\mathrm{M})$, and Srebp1c (N and O) were measured. H4IIEC3 cells were pretreated with rotenone (24 h; $50 \mathrm{nM})$ followed by fructose incubation $(6 \mathrm{~h} ; 5 \mathrm{mM})$, and levels of Acc and Hmgcr mRNA (D, H) were measured $(n=4)$. For cholesterol assays, (I-K) H4IIEC3 cells were incubated with fructose $(1-5 \mathrm{mM})$ or co-incubated with fructose $(5 \mathrm{mM})$ and nicotinamide $(0 \cdot 1-2 \mathrm{mM})$ or fructose $(5 \mathrm{mM})$ and rotenone $(50 \mathrm{nM})$ for $24 \mathrm{~h}$. Data are expressed as mean \pm s.E.M. ${ }^{*} P<0 \cdot 05,{ }^{* *} P<0 \cdot 01,{ }^{* * *} P<0 \cdot 001$ versus untreated control $(\mathrm{U}) ;{ }^{\#} P<0 \cdot 05$, $\# \# P<0 \cdot 001$ versus fructose alone.

We report in this study that SIRT1 activators can induce hepatic lipogenesis. Moreover, liver-specific SIRT1 knockout mice are reported to gain less weight and display lower fat accumulation in liver and WAT compared with wild-type controls, as a result of decreased SIRT1-induced hepatic lipogenesis (Chen et al. 2008). Hence, increased weight gain in high-fat-fed ob/ob mice administered SRT1720 may occur through induction of hepatic lipogenesis.

We also report that fructose incubation results in increased electron transport chain activity, demonstrated by increased $\mathrm{NAD}^{+} / \mathrm{NADH}$ ratio and ATP levels and by the observation that rotenone, an inhibitor of complex I of the electron transport chain, inhibits fructose-induced gluconeogenesis. This is in agreement with previous studies reporting inhibition of fructose-mediated induction of electron transport chain activity and gluconeogenesis (Pryor et al. 1987). However, the mechanisms responsible for fructose-mediated activation of the electron transport chain are unclear. It is widely accepted that hepatic ATP levels fall on exposure to high fructose levels
(Clark et al. 1979, Latta et al. 2000). However, this is based on observations that assessed ATP levels after acute fructose exposure. Consistent with such observations the results of this study show a $\sim 20 \%$ fall after $10-$ min fructose incubation, but ATP increases progressively after $1 \mathrm{~h}$ to reach a level $80 \%$ above baseline at $6 \mathrm{~h}$. The initial fall is probably caused by the first step in hepatocyte fructose metabolism, which involves ATP-dependent fructokinase-catalyzed conversion of fructose to fructose 1-phosphate, as proposed by other authors (Johnson et al. 2007). The rise in ATP coincides with an increase in NAD/ $\mathrm{NADH}$ ratios. It is possible that initial fructose-mediated depletion in ATP levels drives electron transport chain activity, resulting in the later increases in $\mathrm{NAD}^{+} / \mathrm{NADH}$ ratios and consequent induction of SIRT1 and higher ATP levels observed in this study. Other studies have reported an increase in mitochondrial volume following gluconeogenic stimulation leading to stimulation of electron transport chain flux (Pryor et al. 1987). Such a mechanism could be operative in hepatocytes in response to fructose incubation. 
Consumption of a fructose-rich diet has previously been shown to induce de novo lipogenesis leading to elevated triglyceride and cholesterol levels and dyslipidemia (Fiebig et al. 1998, Kelley et al. 2004, Jurgens et al. 2005, Bilz et al. 2006, Rajasekar \& Anuradha 2007, Nagai et al. 2009). We report in this study that fructose induces gene expression of Hmgcr and Acc as well as intracellular cholesterol production through a SIRT1-dependent mechanism. This likely occurs through SIRT1-mediated activation of PGC1 $\beta$ and SREBP1c. Overexpression of hepatic PGC1 $\beta$ has been shown to induce expression of genes for lipid and cholesterol synthesis (Lin et al. 2005), while PGC1 $\beta$ has been reported to mediate the lipogenic effects of both fructose and saturated fat through coactivation fatty acid genes (Lin et al. 2005, Nagai et al. 2009). Furthermore, previous studies have reported that SIRT1 can deacetylate PGC1 $\beta$ in skeletal muscle, inducing the expression of PGC1 $\beta$ gene targets. We provide evidence that a similar mechanism could operate in the liver.

SREBP1c is a key transcription factor for lipogenic genes and is also induced by fructose, potentially through activation of PGC1 $\beta$ and liver X receptor (LXR; Rutledge \& Adeli 2007, Nagai et al. 2009). Moreover, SIRT1 has been demonstrated to activate LXR (Li et al. 2007). In agreement with such observations, hepatic SIRT1 knockout mice have lower levels of lipogenesis and are protected from the negative metabolic effects of a high-fat diet (Chen et al. 2008). PGC1 $\beta$ is reported to induce hepatic lipogenesis through induction of the lipogenic transcription factor SREBP1c and LXR (Lin et al. 2005, Nagai et al. 2009), while SIRT1 has separately been shown to deacetylate and activate LXR (Li et al. 2007, Chen et al. 2008). Whether the deacetylation of LXR by SIRT1 is separate to its action on PGC1 $\beta$ or whether they are part of the same regulatory system requires further investigation.

Conversely, activators of SIRT1, particularly SRT1720, are reported to have anti-diabetic actions and are under investigation as treatments for T2DM, having been shown to reduce blood glucose levels and increase insulin sensitivity in rodent models of diabetes (Milne et al. 2007), potentially by facilitating degradation of CREB-regulated transcription coactivator 2 (CRTC2), a coactivator of gluconeogenic gene expression (Liu et al. 2008). However, this study also reported that following SIRT1-mediated degradation of CRTC2 after short-term fasting, SIRT1 induced gluconeogenic gene expression over a longer fast through a FOXO1mediated mechanism. Additionally, we have previously reported increased SIRT1 following metformin administration in $\mathrm{db} / \mathrm{db}$ mice, associated with reduced gluconeogenesis. However, this observation occurred in parallel with increased levels of GCN5, an acetyl transferase that can inhibit gluconeogenic gene expression. Increases in GCN5 likely masked the gluconeogenic stimulatory effects of SIRT1, while also contributing to the observed reductions in gluconeogenesis (Caton et al. 2010). In addition, reports have highlighted the potential benefits of increased hepatic
SIRT1 for protection against fatty liver through promotion of fatty acid oxidation (Feige et al. 2008, Pfluger et al. 2008, Purushotham et al. 2009). These effects are consistent with induction of PGC1 $\alpha$, which along with SIRT1 is required for activation of peroxisome proliferator-activated receptor-alpha (PPAR $\alpha$; Purushotham et al. 2009), and may account for some of the insulin-sensitizing effects of SIRT1 activators. Despite this, knockdown of hepatic Pgc1 $\alpha$ lowers blood glucose in $\mathrm{db} / \mathrm{db}$ and normal mice, while overexpression of $\operatorname{Pgc} 1 \alpha$ leads to mild hyperglycemia (Rodgers \& Puigserver 2007). Moreover, Pgc1 $\alpha$ knockout mice display increased insulin sensitivity (Burgess et al. 2006).

Nevertheless, the metabolic consequences of SIRT1 activators in the liver have yet to be fully described. In this study, we demonstrated that SIRT1-activating compounds induced gluconeogenesis and lipogenesis in cultured primary hepatocytes, although in the case of SRT1720 it is currently unclear whether this compound activates SIRT1 directly. In this respect, in vivo studies of the effects of direct activators such as SIRT1 activator 3 would be beneficial. Given the data reported in this study and elsewhere, caution should be exercised with respect to the use of SIRT1 activators as therapies for T2DM and metabolic syndrome.

In summary, we have identified fructose as an activator of hepatic SIRT1, raising the possibility that induction of hepatic SIRT1 represents a key process in the onset of metabolic syndrome occurring in response to the consumption of a fructose-rich diet.

\section{Supplementary data}

This is linked to the online version of the paper at http://dx.doi.org/10.1530/ JOE-10-0190.

\section{Declaration of interest}

The authors declare that there is no conflict of interest that could be perceived as prejudicing the impartiality of the research reported.

\section{Funding}

P W C was funded by a Medical Research Council PhD Studentship. This study forms part of the research themes contributing to the translational research portfolio of Bart's and the London Cardiovascular Biomedical Research Unit, which is supported and funded by the National Institute for Health Research.

\section{References}

Abdel-Sayed A, Binnert C, Le KA, Bortolotti M, Schneiter P \& Tappy L 2008 A high-fructose diet impairs basal and stress-mediated lipid metabolism in healthy male subjects. British Journal of Nutrition 100 393-399. (doi:10. 1017/S000711450789547X) 
Aeberli I, Zimmermann MB, Molinari L, Lehmann R, l'Allemand D, Spinas GA \& Berneis K 2007 Fructose intake is a predictor of LDL particle size in overweight schoolchildren. American Journal of Clinical Nutrition $\mathbf{8 6}$ 1174-1178.

Bazzano LA, Li TY, Joshipura KJ \& Hu FB 2008 Intake of fruit, vegetables, and fruit juices and risk of diabetes in women. Diabetes Care 31 1311-1317. (doi:10.2337/dc08-0080)

Bergmeyer HU 1963 Methods of Enzymatic Analysis. Berlin: Verlag Chemie. Bilz S, Samuel V, Morino K, Savage D, Choi CS \& Shulman GI 2006 Activation of the farnesoid $\mathrm{X}$ receptor improves lipid metabolism in combined hyperlipidemic hamsters. American Journal of Physiology. Endocrinology and Metabolism 290 E716-E722. (doi:10.1152/ajpendo.00355 2005)

Blakely SR, Hallfrisch J, Reiser S \& Prather ES 1981 Long-term effects of moderate fructose feeding on glucose tolerance parameters in rats. Journal of Nutrition 111 307-314.

Bray GA, Nielsen SJ \& Popkin BM 2004 Consumption of high-fructose corn syrup in beverages may play a role in the epidemic of obesity. American Journal of Clinical Nutrition 79 537-543.

Burgess SC, Leone TC, Wende AR, Croce MA, Chen Z, Sherry AD, Malloy CR \& Finck BN 2006 Diminished hepatic gluconeogenesis via defects in tricarboxylic acid cycle flux in peroxisome proliferator-activated receptor gamma coactivator-1alpha (PGC-1alpha)-deficient mice. Journal of Biological Chemistry 281 19000-19008. (doi:10.1074/jbc.M600050200)

Caton PW, Nayuni NK, Murch O \& Corder R 2009 Endotoxin induced hyperlactatemia and hypoglycemia is linked to decreased mitochondrial phosphoenolpyruvate carboxykinase. Life Sciences 84 738-744. (doi:10. 1016/j.lfs.2009.02.024)

Caton PW, Nayuni NK, Kieswich J, Khan NQ, Yaqoob MM \& Corder R 2010 Metformin suppresses hepatic gluconeogenesis through induction of SIRT1 and GCN5. Journal of Endocrinology 205 97-106. (doi:10.1677/ JOE-09-0345)

Chen D \& Guarente L 2007 SIR2: a potential target for calorie restriction mimetics. Trends in Molecular Medicine 13 64-71. (doi:10.1016/j.molmed. 2006.12.004)

Chen D, Bruno J, Easlon E, Lin SJ, Cheng HL, Alt FW \& Guarente L 2008 Tissue-specific regulation of SIRT1 by calorie restriction. Genes and Development 22 1753-1757. (doi:10.1101/gad.1650608)

Clark DG, Filsell OH \& Topping DL 1979 Effects of fructose concentration on carbohydrate metabolism, heat production and substrate cycling in isolated rat hepatocytes. Biochemical Journal 184 501-507.

Douthwaite JA, Lees DM \& Corder R 2003 A role for increased mRNA stability in the induction of endothelin-1 synthesis by lipopolysaccharide. Biochemical Pharmacology 66 589-594. (doi:10.1016/ S0006-2952(03)00336-8)

Erion DM, Yonemitsu S, Nie Y, Nagai Y, Gillum MP, Hsiao JJ, Iwasaki T, Stark R, Weismann D, Yu XX et al. 2009 SirT1 knockdown in liver decreases basal hepatic glucose production and increases hepatic insulin responsiveness in diabetic rats. PNAS 106 11288-11293. (doi:10.1073/ pnas.0812931106)

Faeh D, Minehira K, Schwarz JM, Periasamy R, Park S \& Tappy L 2005 Effect of fructose overfeeding and fish oil administration on hepatic de novo lipogenesis and insulin sensitivity in healthy men. Diabetes 54 1907-1913. (doi:10.2337/diabetes.54.7.1907)

Feige JN, Lagouge M, Canto C, Strehle A, Houten SM, Milne JC, Lambert PD, Mataki C, Elliott PJ \& Auwerx J 2008 Specific SIRT1 activation mimics low energy levels and protects against diet-induced metabolic disorders by enhancing fat oxidation. Cell Metabolism 8 347-358. (doi:10. 1016/j.cmet.2008.08.017)

Fiebig R, Griffiths MA, Gore MT, Baker DH, Oscai L, Ney DM \& Ji LL 1998 Exercise training down-regulates hepatic lipogenic enzymes in meal-fed rats: fructose versus complex-carbohydrate diets. Journal of Nutrition 128 810-817.

Frescas D, Valenti L \& Accili D 2005 Nuclear trapping of the forkhead transcription factor FoxO1 via Sirt-dependent deacetylation promotes expression of glucogenetic genes. Journal of Biological Chemistry 280 20589-20595. (doi:10.1074/jbc.M412357200)
Gaby AR 2005 Adverse effects of dietary fructose. Alternative Medicine Review 10 294-306.

Gomez-Valades AG, Vidal-Alabro A, Molas M, Boada J, Bermudez J, Bartrons R \& Perales JC 2006 Overcoming diabetes-induced hyperglycemia through inhibition of hepatic phosphoenolpyruvate carboxykinase (GTP) with RNAi. Molecular Therapy 13 401-410. (doi:10.1016/j.ymthe. 2005.08.026)

Gomez-Valades AG, Mendez-Lucas A, Vidal-Alabro A, Blasco FX, Chillon M, Bartrons R, Bermudez J \& Perales JC 2008 Pck1 gene silencing in the liver improves glycemia control, insulin sensitivity, and dyslipidemia in $\mathrm{db} / \mathrm{db}$ mice. Diabetes 57 2199-2210. (doi:10.2337/db07-1087)

Hobbs HH, Russell DW, Brown MS \& Goldstein JL 1990 The LDL receptor locus in familial hypercholesterolemia: mutational analysis of a membrane protein. Annual Review of Genetics 24 133-170. (doi:10.1146/annurev.ge. 24.120190.001025)

Hollenbeck CB 1993 Dietary fructose effects on lipoprotein metabolism and risk for coronary artery disease. American Journal of Clinical Nutrition $\mathbf{5 8}$ 800S-809S.

Ishdorj G, Graham BA, Hu X, Chen J, Johnston JB, Fang X \& Gibson SB 2008 Lysophosphatidic acid protects cancer cells from histone deacetylase (HDAC) inhibitor-induced apoptosis through activation of HDAC. Journal of Biological Chemistry 283 16818-16829. (doi:10.1074/jbc. M710177200)

Johnson RJ, Segal MS, Sautin Y, Nakagawa T, Feig DI, Kang DH, Gersch MS, Benner S \& Sanchez-Lozada LG 2007 Potential role of sugar (fructose) in the epidemic of hypertension, obesity and the metabolic syndrome, diabetes, kidney disease, and cardiovascular disease. American Journal of Clinical Nutrition 86 899-906.

Jurgens H, Haass W, Castaneda TR, Schurmann A, Koebnick C, Dombrowski F, Otto B, Nawrocki AR, Scherer PE, Spranger J et al. 2005 Consuming fructose-sweetened beverages increases body adiposity in mice. Obesity Research 13 1146-1156. (doi:10.1038/oby.2005.136)

Kain KH, Popov VL \& Herzog NK 2000 Alterations in mitochondria and mtTFA in response to LPS-induced differentiation of B-cells. Biochimica et Biophysica Acta 1494 91-103. (doi:10.1016/S0167-4781(00)00223-2)

Kelley GL, Allan G \& Azhar S 2004 High dietary fructose induces a hepatic stress response resulting in cholesterol and lipid dysregulation. Endocrinology 145 548-555. (doi:10.1210/en.2003-1167)

Landry J, Sutton A, Tafrov ST, Heller RC, Stebbins J, Pillus L \& Sternglanz R 2000 The silencing protein SIR2 and its homologs are NAD-dependent protein deacetylases. PNAS 97 5807-5811. (doi:10.1073/pnas.110148297)

Latta M, Kunstle G, Leist M \& Wendel A 2000 Metabolic depletion of ATP by fructose inversely controls. Journal of Experimental Medicine 191 1975-1985. (doi:10.1084/jem.191.11.1975)

Li X, Zhang S, Blander G, Tse JG, Krieger M \& Guarente L 2007 SIRT1 deacetylates and positively regulates the nuclear receptor LXR. Molecular Cell 28 91-106. (doi:10.1016/j.molcel.2007.07.032)

Lin J, Yang R, Tarr PT, Wu PH, Handschin C, Li S, Yang W, Pei L, Uldry M, Tontonoz $\mathrm{P}$ et al. 2005 Hyperlipidemic effects of dietary saturated fats mediated through PGC-1beta coactivation of SREBP. Cell 120 261-273. (doi:10.1016/j.cell.2004.11.043)

Liu Y, Dentin R, Chen D, Hedrick S, Ravnskjaer K, Schenk S, Milne J, Meyers DJ, Cole P, Yates J III et al. 2008 A fasting inducible switch modulates gluconeogenesis via activator/coactivator exchange. Nature 456 269-273. (doi:10.1038/nature07349)

Malik VS, Popkin BM, Bray GA, Després JP, Willett WC \& Hu FB 2010 Sugar-sweetened beverages and risk of metabolic syndrome and type 2 diabetes: a meta-analysis. Diabetes Care 33 2477-2483. (doi:10.2337/ dc10-1079)

Marmorstein R 2004 Structure and chemistry of the Sir2 family of NAD ${ }^{+}$dependent histone/protein deactylases. Biochemical Society Transactions 32 904-909. (doi:10.1042/BST0320904)

Mayes PA 1993 Intermediary metabolism of fructose. American Journal of Clinical Nutrition 58 754S-765S.

Michan S \& Sinclair D 2007 Sirtuins in mammals: insights into their biological function. Biochemical Journal 404 1-13. (doi:10.1042/BJ20070140) 
Milne JC, Lambert PD, Schenk S, Carney DP, Smith JJ, Gagne DJ, Jin L, Boss O, Perni RB, Vu CB et al. 2007 Small molecule activators of SIRT1 as therapeutics for the treatment of type 2 diabetes. Nature $\mathbf{4 5 0}$ 712-716. (doi:10.1038/nature06261)

Moynihan KA, Grimm AA, Plueger MM, Bernal-Mizrachi E, Ford E, Cras-Meneur C, Permutt MA \& Imai S 2005 Increased dosage of mammalian Sir2 in pancreatic beta cells enhances glucose-stimulated insulin secretion in mice. Cell Metabolism 2 105-117. (doi:10.1016/j. cmet.2005.07.001)

Nagai Y, Yonemitsu S, Erion DM, Iwasaki T, Stark R, Weismann D, Dong J, Zhang D, Jurczak MJ, Loffler MG et al. 2009 The role of peroxisome proliferator-activated receptor gamma coactivator-1 beta in the pathogenesis of fructose-induced insulin resistance. Cell Metabolism 9 252-264. (doi:10.1016/j.cmet.2009.01.011)

Nakagawa T, Hu H, Zharikov S, Tuttle KR, Short RA, Glushakova O, Ouyang X, Feig DI, Block ER, Herrera-Acosta J et al. 2006 A causal role for uric acid in fructose-induced metabolic syndrome. American Journal of Physiology. Renal Physiology 290 F625-F631. (doi:10.1152/ajprenal.00140. 2005)

Napper AD, Hixon J, McDonagh T, Keavey K, Pons JF, Barker J, Yau WT, Amouzegh P, Flegg A, Hamelin E et al. 2005 Discovery of indoles as potent and selective inhibitors of the deacetylase SIRT1. Journal of Medicinal Chemistry 48 8045-8054. (doi:10.1021/jm050522v)

Nayagam VM, Wang X, Tan YC, Poulsen A, Goh KC, Ng T, Wang H, Song HY, Ni B, Entzeroth M et al. 2006 SIRT1 modulating compounds from high-throughput screening as anti-inflammatory and insulin-sensitizing agents. Journal of Biomolecular Screening 11 959-967. (doi:10.1177/1087057106294710)

Nie Y, Erion DM, Yuan Z, Dietrich M, Shulman GI, Horvath TL \& Gao Q 2009 STAT3 inhibition of gluconeogenesis is downregulated by SirT1. Nature Cell Biology 11 492-500. (doi:10.1038/ncb1857)

Pacholec M, Bleasdale JE, Chrunyk B, Cunningham D, Flynn D, Garofalo RS, Griffith D, Griffor M, Loulakis P, Pabst B et al. 2010 SRT1720, SRT2183, SRT1460, and resveratrol are not direct activators of SIRT1. Journal of Biological Chemistry 285 8340-8351. (doi:10.1074/jbc.M109.088682)

Pagliassotti MJ, Wei Y \& Bizeau ME 2003 Glucose-6-phosphatase activity is not suppressed but the mRNA level is increased by a sucrose-enriched meal in rats. Journal of Nutrition 133 32-37.

Parks EJ, Skokan LE, Timlin MT \& Dingfelder CS 2008 Dietary sugars stimulate fatty acid synthesis in adults. Journal of Nutrition 138 1039-1046.

Pfluger PT, Herranz D, Velasco-Miguel S, Serrano M \& Tschop MH 2008 Sirt1 protects against high-fat diet-induced metabolic damage. PNAS 105 9793-9798. (doi:10.1073/pnas.0802917105)

Pillai JB, Chen M, Rajamohan SB, Samant S, Pillai VB, Gupta M \& Gupta MP 2008 Activation of SIRT1, a class III histone deacetylase, contributes to fructose feeding-mediated induction of the alpha-myosin heavy chain expression. American Journal of Physiology. Heart and Circulatory Physiology 294 H1388-H1397. (doi:10.1152/ajpheart.01339.2007)

Pryor HJ, Smyth JE, Quinlan PT \& Halestrap AP 1987 Evidence that the flux control coefficient of the respiratory chain is high during gluconeogenesis from lactate in hepatocytes from starved rats. Implications for the hormonal control of gluconeogenesis and action of hypoglycaemic agents. Biochemical Journal 247 449-457.
Purushotham A, Schug TT, Xu Q, Surapureddi S, Guo X \& Li X 2009 Hepatocyte-specific deletion of SIRT1 alters fatty acid metabolism and results in hepatic steatosis and inflammation. Cell Metabolism 9 327-338. (doi:10.1016/j.cmet.2009.02.006)

Rajasekar P \& Anuradha CV 2007 Fructose-induced hepatic gluconeogenesis: effect of L-carnitine. Life Sciences 80 1176-1183. (doi:10.1016/j. lfs.2006.12.010)

Rodgers JT \& Puigserver P 2007 Fasting-dependent glucose and lipid metabolic response through hepatic sirtuin 1. PNAS 104 12861-12866. (doi:10.1073/pnas.0702509104)

Rodgers JT, Lerin C, Haas W, Gygi SP, Spiegelman BM \& Puigserver P 2005 Nutrient control of glucose homeostasis through a complex of PGC-1alpha and SIRT1. Nature 434 113-118. (doi:10.1038/nature03354)

Rutledge AC \& Adeli K 2007 Fructose and the metabolic syndrome: pathophysiology and molecular mechanisms. Nutrition Reviews 65 S13-S23. (doi:10.1301/nr.2007.jun.S13-S23)

San KY, Bennett GN, Berrios-Rivera SJ, Vadali RV, Yang YT, Horton E, Rudolph FB, Sariyar B \& Blackwood K 2002 Metabolic engineering through cofactor manipulation and its effects on metabolic flux redistribution in Escherichia coli. Metabolic Engineering 4 182-192. (doi:10.1006/mben.2001.0220)

Stanhope KL, Schwarz JM, Keim NL, Griffen SC, Bremer AA, Graham JL, Hatcher B, Cox CL, Dyachenko A, Zhang W et al. 2009 Consuming fructose-sweetened, not glucose-sweetened, beverages increases visceral adiposity and lipids and decreases insulin sensitivity in overweight/obese humans. Journal of Clinical Investigation 119 1322-1334. (doi:10.1172/ JCI37385)

Sun Y, Liu S, Ferguson S, Wang L, Klepcyk P, Yun JS \& Friedman JE 2002 Phosphoenolpyruvate carboxykinase overexpression selectively attenuates insulin signaling and hepatic insulin sensitivity in transgenic mice. Journal of Biological Chemistry 277 23301-23307. (doi:10.1074/jbc.M200964200)

Valera A, Pujol A, Pelegrin M \& Bosch F 1994 Transgenic mice overexpressing phosphoenolpyruvate carboxykinase develop non-insulindependent diabetes mellitus. PNAS 91 9151-9154. (doi:10.1073/pnas.91. 19.9151)

Voet D \& Voet JG 1994 Biochemistry, 2nd edn. New York, USA: John Wiley and Sons, Inc.

Wei Y \& Pagliassotti MJ 2004 Hepatospecific effects of fructose on c-jun $\mathrm{NH}_{2}$-terminal kinase: implications for hepatic insulin resistance. American Journal of Physiology. Endocrinology and Metabolism 287 E926-E933. (doi:10. 1152/ajpendo.00185.2004)

Wei Y, Wang D \& Pagliassotti MJ 2005 Fructose selectively modulates c-jun $\mathrm{N}$-terminal kinase activity and insulin signaling in rat primary hepatocytes. Journal of Nutrition 135 1642-1646.

\section{Received in final form 3 December 2010}

Accepted 6 January 2011

Made available online as an Accepted Preprint 6 January 2011 